\title{
Cell Cycle Inhibition Preserves Endothelial Function in Genetically Engineered Rabbit Vein Grafts
}

\author{
Michael J. Mann, ${ }^{\star \ddagger}$ Gary H. Gibbons, ${ }^{\star}$ Philip S. Tsao, ${ }^{\S}$ Heiko E. von der Leyen, ${ }^{\S}$ John P. Cooke, ${ }^{\S}$ Ricardo Buitrago, ${ }^{\S}$ \\ Rachel Kernoff, ${ }^{\S}$ and Victor J. Dzau* \\ *Division of Cardiovascular Medicine, Brigham and Women's Hospital/Harvard Medical School, Boston, Massachusetts 02115; \\ ${ }^{\ddagger}$ Department of Surgery, Stanford University School of Medicine, Stanford, California 94305; and ${ }^{\S}$ Division of Cardiovascular Medicine, \\ Falk Cardiovascular Research Center, Stanford University School of Medicine, Stanford, California 94305
}

\begin{abstract}
We have recently shown that ex vivo gene therapy of rabbit autologous vein grafts with antisense oligodeoxynucleotides (AS ODN) blocking cell cycle regulatory gene expression inhibits not only neointimal hyperplasia, but also diet-induced, accelerated graft atherosclerosis. We observed that these grafts remained free of macrophage invasion and foam cell deposition. Since endothelial dysfunction plays an important role in vascular disease, the current study examined the effect of this genetic engineering strategy on graft endothelial function and its potential relationship to the engineered vessels' resistance to atherosclerosis. Rabbit vein grafts transfected with AS ODN against proliferating cell nuclear antigen (PCNA) and cell division cycle 2 (cdc2) kinase elaborated significantly more nitric oxide and exhibited greater vasorelaxation to both calcium ionophore and acetylcholine than did untreated or control ODN-treated grafts. This preservation of endothelial function was associated with a reduction in superoxide radical generation, vascular cell adhesion molecule-1 (VCAM-1) expression, and monocyte binding activity in grafts in both normal and hypercholesterolemic rabbits. Our data demonstrate that AS ODN arrest of vascular cell cycle progression results in the preservation of normal endothelial phenotype and function, thereby influencing the biology of the vessel wall towards a reduction of its susceptibility to occlusive disease. (J. Clin. Invest. 1997. 99:1295-1301.) Key words: gene therapy • cell cycle $\bullet$ endothelium - cardiovascular surgery $\bullet$ antisense oligonucleotides
\end{abstract}

\section{Introduction}

Autologous vein graft failure, due primarily to an aggressive form of atherosclerosis, remains a significant limitation to the long-term treatment of occlusive vascular disease $(1,2)$. We have recently reported an ex vivo gene therapy strategy that produced vein grafts resistant to this accelerated atherogenesis

Address correspondence to Victor J. Dzau, M.D., Brigham and Women's Hospital, Cardiovascular Research-Thorn 12, 75 Francis Street, Boston, MA 02115. Phone: 617-732-6340; FAX: 617-975-0995; E-mail:vdzau@bics.bwh.harvard.edu

Received for publication 17 April 1996 and accepted in revised form 2 January 1997.

J. Clin. Invest.

(C) The American Society for Clinical Investigation, Inc.

0021-9738/97/03/1295/07 \$2.00

Volume 99, Number 6, March 1997, 1295-1301 in cholesterol-fed New Zealand White rabbits (3). This strategy utilizes the transfection of vein graft wall with antisense oligodeoxynucleotides (AS ODN $)^{1}$ that block the expression of two cell cycle regulatory genes-proliferating cell nuclear antigen (PCNA) and cell division cycle 2 (cdc2) kinase. The subsequent arrest of smooth muscle cell (SMC) proliferation inhibited neointima formation for up to $10 \mathrm{wk}$ after surgery, during which time the grafts instead developed medial hypertrophy as an adaptation to increased hemodynamic stress, acquiring mechanical properties and architecture resembling those of normal arteries. Furthermore, AS ODN-treated grafts proved resistant to the formation of diet-induced atherosclerotic plaque.

Endothelial dysfunction is believed to play a critical role in the early stages of atheroma formation in native arteries, and is associated with the development of severe neointimal lesions in human vein grafts (4-7). Cell cycle inhibition in the graft wall may therefore prevent intimal lesion development not only by a direct blockade of smooth muscle cell proliferation, but also by an indirect effect of improved endothelial function. Neointimal hyperplasia after injury has been associated with an altered phenotypic state of vascular cells (8). This altered, or activated, state is characterized by the expression of adhesion molecules and cytokines (9-11), and produces a significantly different molecular environment from that of the quiescent media and endothelium of a normal vessel. The cytokines and growth factors released after vascular injury can themselves contribute to further endothelial activation and abnormality $(12,13)$. We hypothesize that the dysfunction of vein graft endothelium is due to a mechanical and/or biochemical activation of the endothelial cells, and that blockade of cell cycle regulatory gene expression inhibits endothelial dysfunction either by a direct effect on endothelial cells, or indirectly by altering the paracrine expression of cytokines and growth factors by the underlying activated SMC.

The two major targets for cell cycle inhibition and phenotypic modulation in the vessel wall are the endothelium and SMC. Our previous data suggested that blockade of cell cycle progression resulted in a prolonged resistance to macrophage invasion and foam cell deposition in the graft wall. Accordingly, in this study, we tested the hypothesis that cell cycle blockade not only prevents SMC proliferation, but also improves endothelial function in the vein graft. The restoration

1. Abbreviations used in this paper: AS, antisense; cdc2, cell division cycle 2; ecNOS, endothelial cell nitric oxide synthetase; HVJ, hemagglutinating virus of Japan; L-NAME, L-nitroarginine methyl ester; ODN, oligodeoxynucleotides; PCNA, proliferating cell nuclear antigen; SMC, smooth muscle cells; VCAM-1, vascular cell adhesion molecule-1. 
of endothelial nitric oxide (NO) synthesis in arteries is associated with the prevention and even regression of atherogenesis (14). Transfection of medial SMC in vivo with the endothelial cell nitric oxide synthase (ecNOS) gene after carotid balloon injury enhances NO elaboration, restores vasoreactivity, and inhibits neointimal hyperplasia (15). In this study, we examined the effect of PCNA/cdc2 kinase AS ODN treatment on the endothelial function of vein grafts, and correlated our findings with other known determinants of atherogenesis (such as vessel wall superoxide radical generation and monocyte adhesiveness).

\section{Methods}

Oligonucleotides and HVJ-liposome preparation. Vein graft transfection was carried out via encapsulation of phosphorothioate ODN (Genta, Inc., San Diego, CA) into neutral liposomes complexed with inactivated hemagglutinating virus of Japan (HVJ) particles, as previously described (16). The following ODN antisense sequences for PCNA and cdc2 kinase were previously shown to inhibit expression of these genes in rabbit cells both in vivo and in vitro in a sequencespecific manner: PCNA, 5'-GATCAGGCGTGCCTCAAA-3'; cdc 2 kinase, 5'-GTCTTCCATAGTTACTCA-3' (3).

Vein grafting and transfection. New Zealand White rabbits (2.5-3 $\mathrm{kg}$ ) underwent jugular vein to carotid artery reverse interposition grafting under ketamine/xylazine anesthesia as previously described (3). Briefly, $2-3 \mathrm{~cm}$ of jugular vien were dissected, and all side branches were ligated via a midline neck incision. Untreated grafts were then harvested and anastamosed into the divided ipsilateral common carotid with interrupted 7-0 polypropylene sutures. Transfected grafts were cannulated via the external branch prior to harvest, flushed with normal saline, and isolated from the circulation. HVJ-liposome complexes in suspension were then infused and incubated at $100 \mathrm{mmHg}$ for $\sim 20 \mathrm{~min}$. Animals were heparinized prior to clamping of the carotid, and grafts were treated topically with $1 \mathrm{ml}$ of $2 \%$ lidocaine solution before wound closure. Complete reendothelialization by the second post-operative week of any graft areas denuded during surgery had been previously documented in this model $(3,17)$. Some animals were maintained on a $1 \%$ cholesterol diet (Dyets, Inc., Bethlehem, PA) for 1 wk before surgery and until the time of harvest, with serum cholesterol levels ranging from 800 to $2,000 \mathrm{mg} / \mathrm{dl}$ during that time period. All animal care complied with Guide for the Care and Use of Laboratory Animals (NIH Publication 80-23, revised 1985).

Vascular reactivity studies. Vascular reactivity in vein grafts, carotid arteries, and jugular veins was measured $6 \mathrm{wk}$ after surgery as previously described (18). Vessels were divided into $5 \mathrm{~mm}$ rings and suspended in physiologic solution between metal hooks attached to a force transducer. Length-tension studies defined an optimal resting tension of $2 \mathrm{~g}$ to achieve maximal norepinephrine (NE)-induced contraction. Increasing concentrations of NE (from $10^{-9}$ to $10^{-4} \mathrm{M}$ ) were administered, and isometric force was continuously recorded. After reequilibration over 30-45 $\mathrm{min}$ in the absence of NE, a sub-maximal contraction was induced by NE. Progressively increasing concentrations of acetylcholine (Ach) or calcium ionophore A23187 were administered to study NO-dependent vasodilation. Relaxation is shown as a percentage of contraction prior to Ach or A23187 exposure.

Endothelial cell nitric oxide synthase (ecNOS) activity. Vein grafts were harvested $4 \mathrm{wk}$ after surgery, rinsed with normal saline, divided transversely into four equal segments and placed into Dulbecco's modified Eagle medium (DMEM)/F12 (GIBCO BRL, Gaithersburg, $\mathrm{MD}$ ), and supplemented with $5 \mu \mathrm{g} / \mathrm{ml}$ transferrin, $0.2 \mathrm{mM}$ ascorbic acid, and $0.5 \mu \mathrm{M}$ insulin (defined serum-free medium, DSF). Alternating segments were then either maintained in DSF for $4 \mathrm{~h}$, or treated with calcium ionophore A23187 $\left(10^{-6} \mathrm{M}\right)$ in DSF to stimulate ecNOS production of NO. Aliquots of conditioned media were then analyzed by chemiluminescence for nitrogen oxide (NOx) content as previously described (18). Values obtained from samples incubated in DSF alone were subtracted from calcium ionophore-treated samples to derive a value for stimulated NOx production, and ecNOS activity was calculated as stimulated NO produced per $\mathrm{mm}^{2}$ tissue surface area per hour incubation.

Superoxide anion measurement. Vein grafts and ungrafted carotid and jugular vessels were harvested from animals $4 \mathrm{wk}$ after surgery, flushed gently with normal saline, and divided transversely into two segments. Tissues were then placed in a phosphate-buffered saline ( $\mathrm{pH}$ 7.4) containing $250 \mu \mathrm{M}$ lucigenin (Sigma Chemical Co., St. Louis, MO). Luminescence was measured in a luminometer (model TD-20e; Turner Designs Inc., Mountain View, CA), and total luminescence over $1 \mathrm{~min}$ was recorded after a $30 \mathrm{sec}$ equilibration period. Superoxide radical generation had previously been found to be linearly proportional to luminescence as expressed in Turner light units (TLU) per minute in the range of activity measured, and this activity was quenched by introduction of superoxide dismutase. Superoxide generation by tissue samples was normalized for tissue wet weight.

Monocyte binding assay. Vein grafts, ungrafted jugular and carotid vessels, and segments of thoracic aortae were harvested $4 \mathrm{wk}$ after surgery and divided into two equal segments longitudinally. For some vessels, monocyte binding was measured immediately in one segment, while the other was incubated for $24 \mathrm{~h}$ in DMEM/F12 medium with $10 \%$ calf serum before assay. No significant difference between monocyte binding at these two time points was detected (data not shown). For other vessels, both segments were kept in organ culture for $24 \mathrm{~h}$ before assay, one being treated with L-nitroarginine methyl ester (L-NAME, Sigma), an inhibitor of NOS at a concentration of $10^{-5} \mathrm{M}$. Monocyte binding per hpf was measured as previously described (19). Briefly, vessel segments were pinned with the endothelial surface facing upward on 5\% agarose gels in Hanks' buffered salt solution (HBSS, GIBCO BRL) and rocked gently for $15 \mathrm{~min}$. The segments were washed with HBSS, and $2 \mathrm{ml}$ of a suspension of THP-1 cells (a human monocyte cell line) that had been loaded for $15 \mathrm{~min}$ with TRITC fluorescent dye (Molecular Probes, Inc., Eugene, OR) was applied to the vessel segments in HBSS supplemented with $\mathrm{Ca}^{++}$ $(2 \mathrm{mM})$ and $\mathrm{Mg}^{++}(2 \mathrm{mM})$ at a concentration of $10^{6}$ cells $/ \mathrm{ml}$. Previous studies have established that the THP-1 cells and rabbit monocytes exhibit similar binding behavior to rabbit endothelium (data not shown). THP-1 cell viability was monitored after dye loading via trypan blue exclusion. The vessel segments were rocked gently for 30 min with intermittent rotation, and then rinsed free of non-adherent THP-1 cells with fresh HBSS. Vessel segments were then examined with fluorescent microscopy for labeled THP-1 cells binding to the vessel surface. To account for variation in monocyte binding between assays, monocyte binding to each graft, jugular vein, and aorta was normalized for the level of binding to the contralateral carotid.

VCAM-1 immunohistochemistry. Vein grafts harvested at $2(n=$ $4)$ and $4(n=5)$ wk after surgery were rinsed gently with normal saline and then snap frozen in OCT. 5- $\mu \mathrm{m}$ sections were fixed in acetone and stained with Rb1/9 (kindly provided by Dr. Myron Cybulski), a monoclonal antibody that recognizes rabbit VCAM-1 using an immunoperoxidase technique. Four sections taken from even intervals were examined from each vessel, and adjacent sections were also stained with a polyclonal antibody for factor VIII antigen (Atlantic Antibodies, Stillwater, MN) using a secondary antibody conjugated to alkaline phosphatase. IgG and sera from appropriate species were used as controls, and some sections were counterstained with hematoxylin (Zymed, South San Francisco, CA).

Segments of untreated, control ODN-treated and AS ODNtreated grafts, and of thoracic aorta from five animals in each group, were treated in organ culture (DMEM/F12 with $10 \%$ calf serum) with lipopolysaccharide $\left(10^{-5} \mathrm{~g} / \mathrm{ml}\right)$ for 24 hours before snap freezing in OCT and sectioning for VCAM-1 immunohistochemical staining. Control segments were frozen at the time of harvest for comparison.

Statistical analysis. Data were obtained from four to six animals in each experimental group as indicated. Results are expressed as 
A

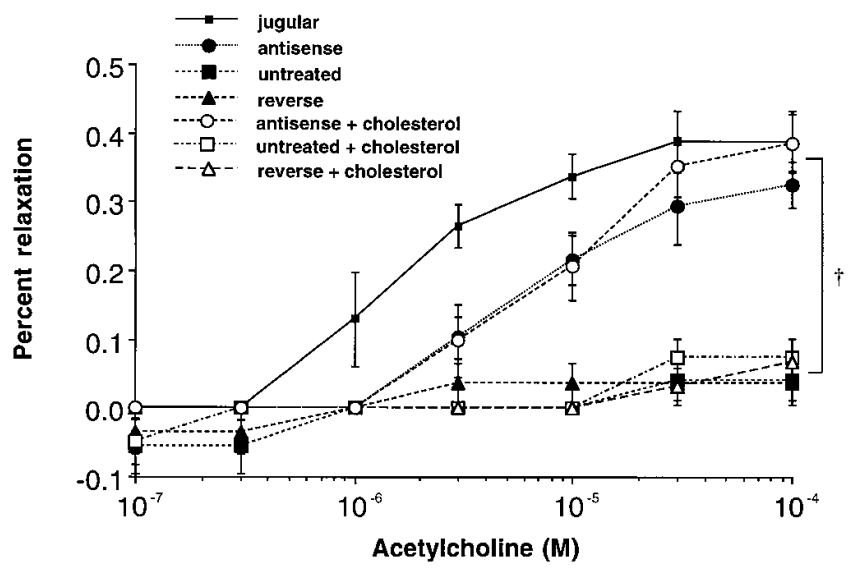

B

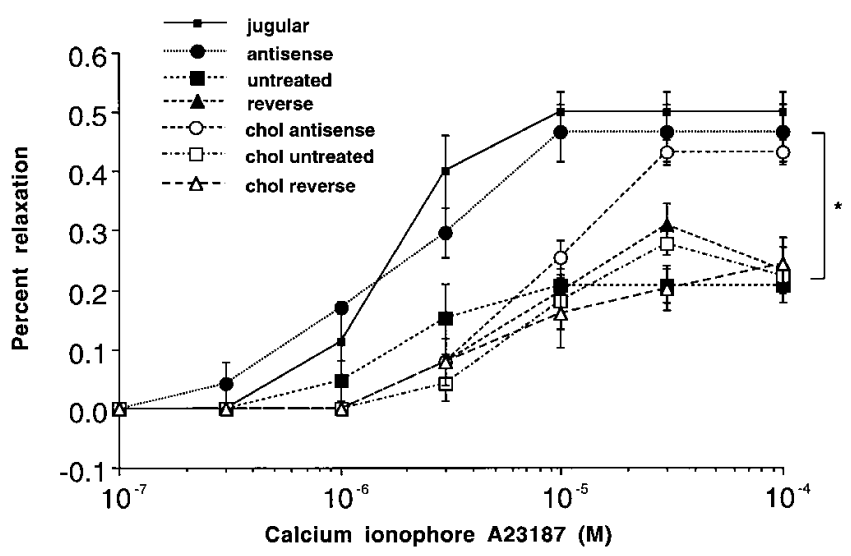

C

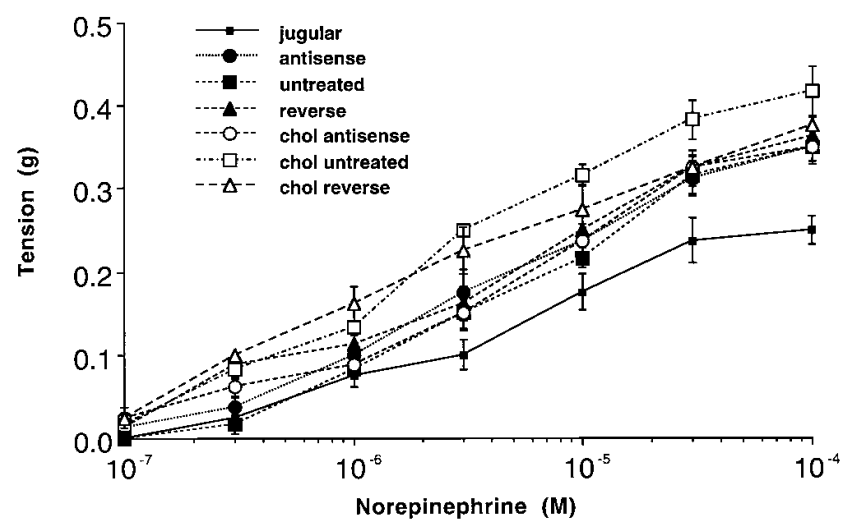

Figure 1. Dose-response curves of untreated, reverse ODN-treated, and AS ODN-treated vein grafts and of jugular vein to acetylcholine $(A)$, calcium ionophore $\mathrm{A} 23187(B)$, and norepinephrine $(C)$. Grafts were harvested at six weeks after surgery from normal (closed symbols) and hypercholesterolemic (open symbols) rabbits. Rings were mounted in an organ chamber for continuous reading of isometric force, and exposed to increasing doses of vasoactive agents as described. $n=4$ for each group. Values are mean \pm SE. ${ }^{\dagger} P<0.005, * P<$ 0.01 for AS ODN-treated graft vs. control grafts. mean values for the different animals in each group \pm SEM. Means were compared using an analysis of variance, and values were considered to be statistically significantly different when $P<0.05$.

\section{Results}

Previous studies have documented the natural history of neointimal and atherosclerotic lesion formation in this model of rabbit vein grafting $(3,17,20)$. Furthermore, we have demonstrated that PCNA and cdc2 kinase expression is upregulated in control grafts during the postoperative period, and that our AS ODN transfection method is effective in blocking both this increased gene expression as well as neointimal hyperplasia in a sequence-specific manner for up to $10 \mathrm{wk}$ (3). In addition to this documented inhibition of neointima forma-

\section{A}

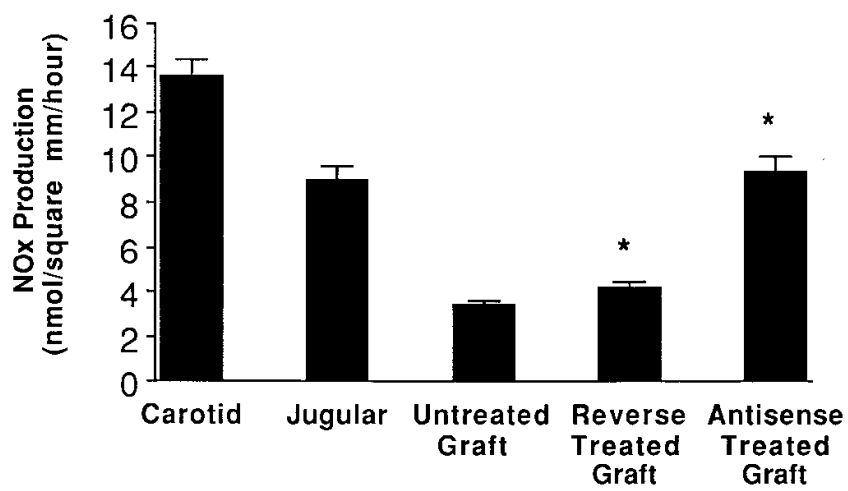

B

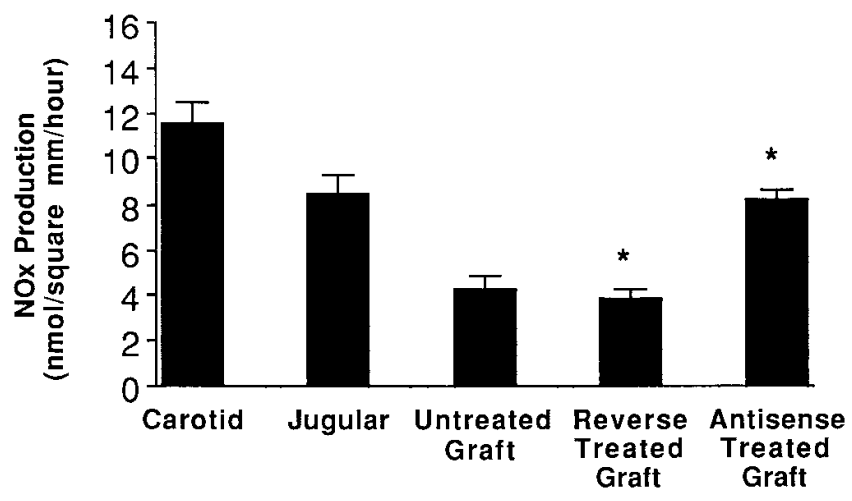

Figure 2. Calcium ionophore stimulated generation of NO in untreated, reverse antisense ODN-treated and AS ODN-treated vein grafts and in carotid artery and jugular vein in normal $(A)$ and hypercholesterolemic $(B)$ rabbits. Tissues were harvested four weeks after surgery, and treated with calcium ionophore A23187 in an ex vivo organ culture for $4 \mathrm{~h}$ to stimulate ecNOS generation of NO. NOx measurements of conditioned media from A23187-treated vessels were made via chemiluminescence, and baseline NOx generated in untreated vessels was subtracted to yield ecNOS production of NO. $n=$ $5,{ }^{*} P<0.001$ for AS ODN-treated graft compared to reverse antisense-treated grafts. 
tion, vein grafts transfected ex vivo with AS ODN directed against PCNA and cdc2 kinase retained a significantly higher degree of vasoresponsiveness at $6 \mathrm{wk}$ to acetylcholine and to calcium ionophore A23187 in both normal and hypercholesterolemic rabbits than did either untreated or control ODN-treated grafts (Fig. 1). The dose-response curves of the genetically engineered grafts for both of these agents remained similar to those of ungrafted vein. Vasoreactive responses to norepinephrine were increased in all vein grafts compared to ungrafted veins, but no significant difference was seen among the responses of untreated, control ODN-treated, and AS ODNtreated grafts. Taken together, these data indicate a relative preservation of normal endothelial function in AS ODNtreated grafts. Endothelial cell NOS is a calcium/calmodulindependent enzyme, and we assayed ecNOS-mediated NO production by measuring calcium ionophore stimulated NOx generation. In accordance with our vasoreactivity data, we observed increased calcium-dependent NOx generation in AS

A

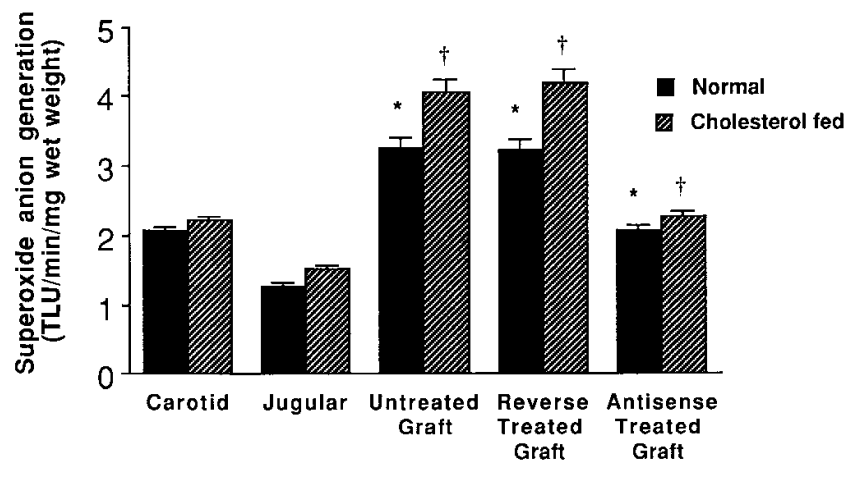

B

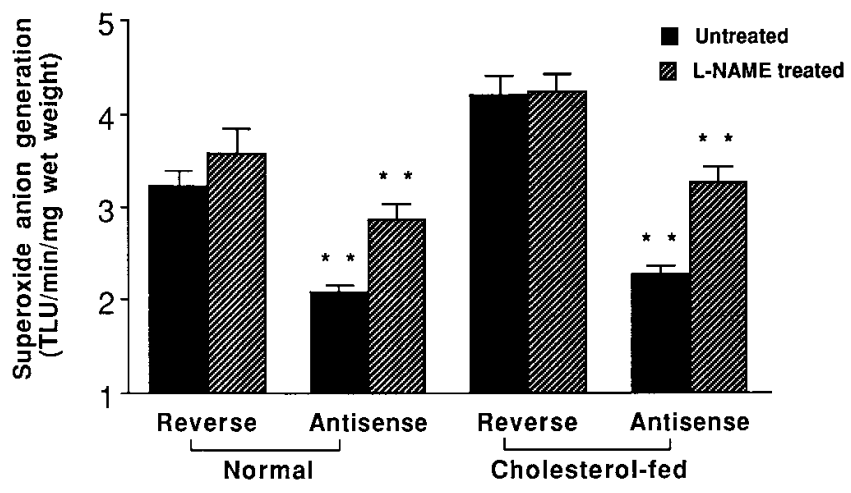

Figure 3. Superoxide radical generation in untreated, reverse antisense ODN-treated and AS ODN-treated vein grafts and in carotid artery and jugular vein in normal and hypercholesterolemic rabbits. Tissues were harvested four weeks after surgery, and superoxide anion generation was measured via lucigenin assay $(A)$. Adjacent segments were also treated ex vivo with L-NAME, an inhibitor of NOS, before measurement of superoxide anion generation $(B) . n=4$, ${ }^{* \dagger} P<0.001$ for AS ODN-treated graft compared to reverse antisense-treated and untreated grafts; ** $P<0.005$ for AS ODN plus L-NAME-treated graft compared to AS ODN-treated grafts.

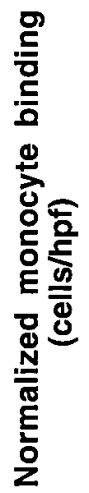

B

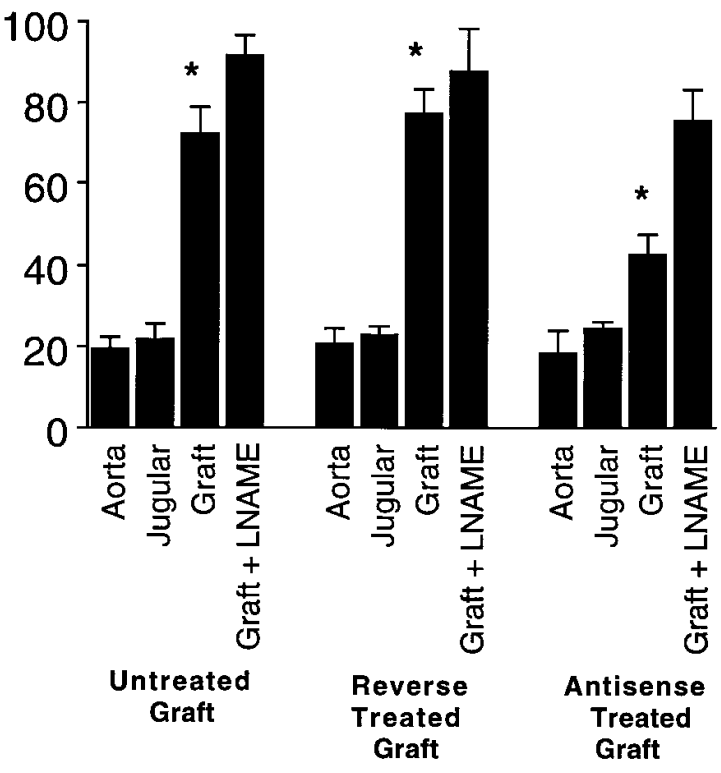

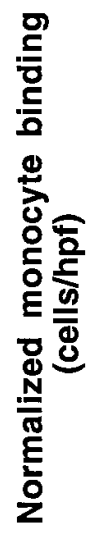

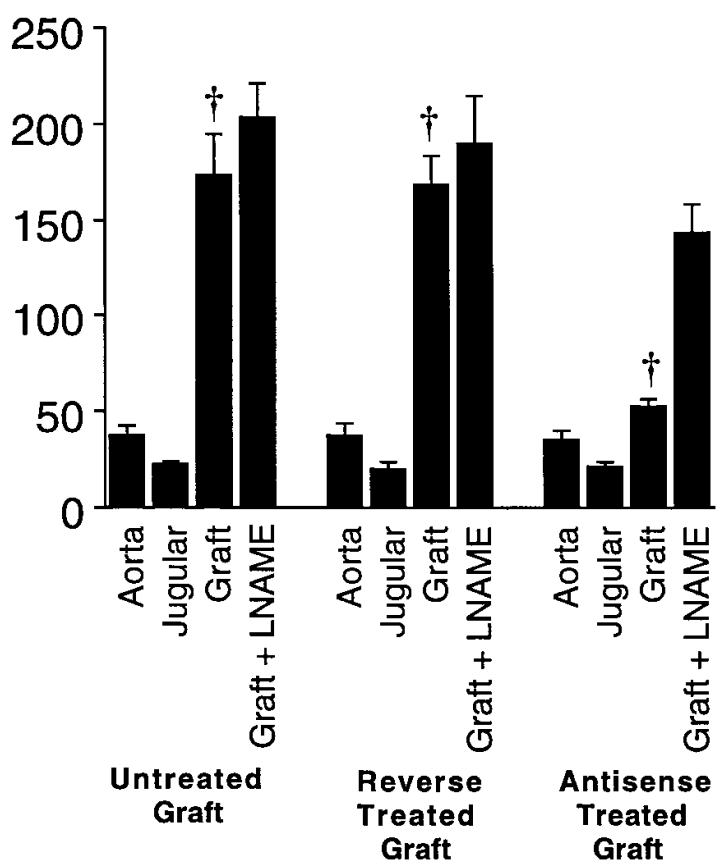

Figure 4. Monocyte binding to endothelial surfaces of untreated, reverse antisense ODN-treated and AS ODN-treated vein grafts, and of aorta and jugular vein in normal $(A)$ and hypercholesterolemic $(B)$ rabbits. Vessels were mounted on agarose gels and exposed to TRITC-labeled THP-1 cells as described $4 \mathrm{wk}$ after surgery. Monocyte binding was measured via fluorescent microscopy, and is expressed as bound cells per high-powered field. Values were normalized for levels of monocyte binding to the ipsilateral carotid to account for variability between assays. Adjacent segments were treated ex vivo with L-NAME, an inhibitor of NOS, prior to measurement of monocyte binding. $n=5,{ }^{*} P<0.001,{ }^{\dagger} P<0.0005$ for AS ODN-treated graft vs. reverse antisense-treated and untreated grafts. 
ODN-treated grafts as compared to either untreated or control ODN-treated grafts (Fig. 2), indicating that the preservation of endothelial function is correlated with increased ecNOS activity.

In addition to reduced endothelium-mediated vasoreactivity, increased superoxide anion generation has also been documented in hypercholesterolemic rabbit vessels (21). This important mediator of oxidative stress was found to be increased
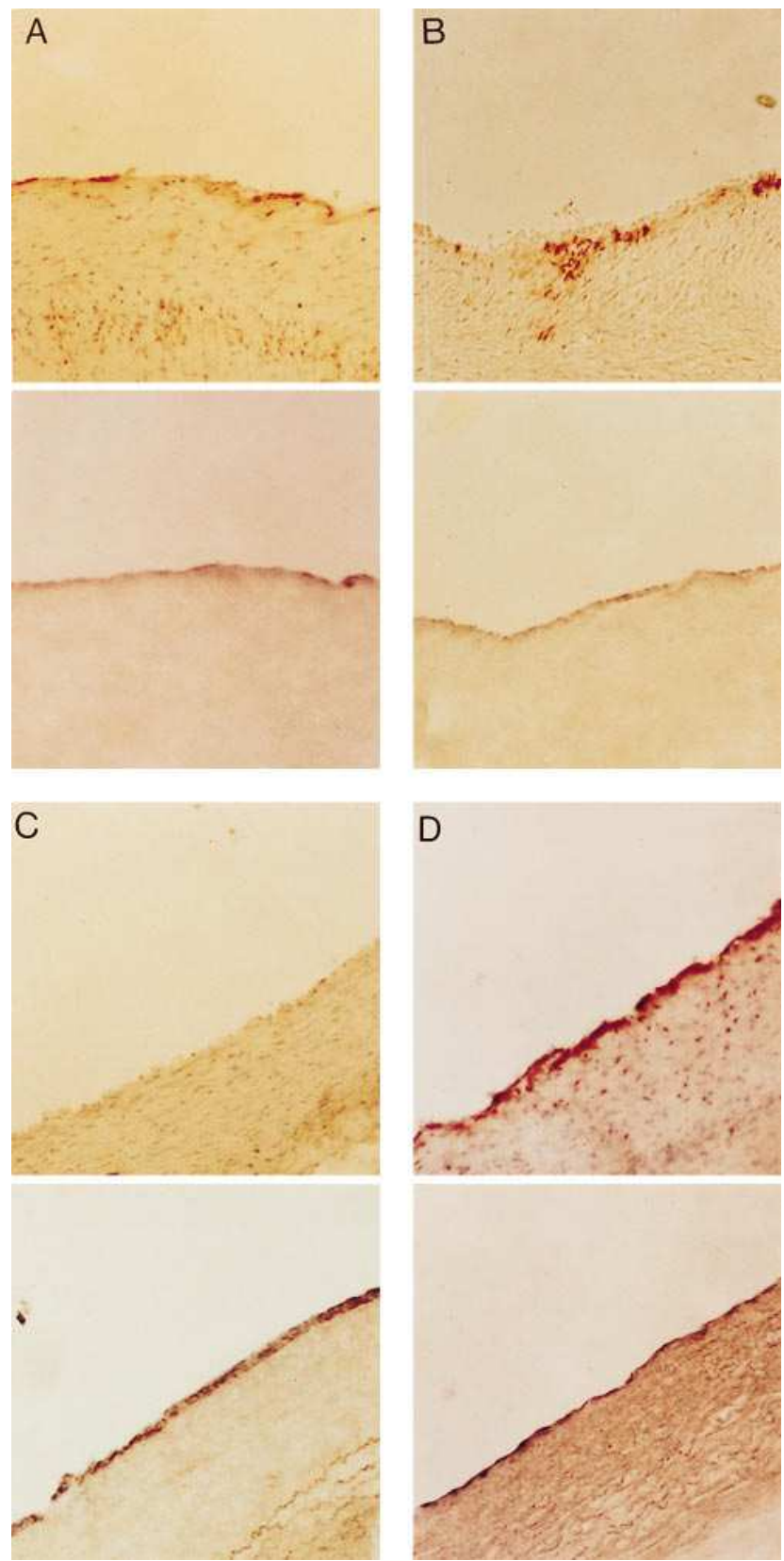

Figure 5. VCAM-1 expression in untreated $(A)$, reverse antisense ODN-treated $(B)$, and AS ODN-treated $(C)$ vein grafts 4 wk after surgery. Grafts $(n=5)$ were snap-frozen in OCT, and 5- $\mu$ m adjacent sections were stained with Rb1/9, a monoclonal antibody against rabbit VCAM-1 (upper panels), and with an antibody to Factor VIII antigen (lower panels). Segments of AS ODN-treated grafts were also treated ex vivo with LPS prior to freezing in OCT to demonstrate these grafts' ability to upregulate VCAM-1 expression $(D)$. in control ODN-treated and untreated grafts when compared to either normal jugular or carotid tissue (Fig. $3 A$ ). Control grafts implanted in cholesterol-fed rabbits were found to have even more pronounced increases in superoxide production. In AS ODN-treated grafts that displayed increased ecNOS activity (and that were less susceptible to diet-induced atherogenesis), superoxide production was found to be reduced by $35 \pm 5 \%$ compared to control ODN-treated grafts under normal diet conditions, and by $45 \pm 7 \%$ in hypercholesterolemic rabbits. Conversely, ex vivo treatment of AS ODN-treated grafts for $4 \mathrm{~h}$ with L-NAME, an inhibitor of NOS, increased oxygen radical generation by $25 \pm 4 \%$ and by $31 \pm 5 \%$ in normal and hypercholesterolemic rabbits, respectively (Fig. $3 \mathrm{~B}$ ).

High levels of monocyte binding to the endothelial surfaces of untreated and control ODN-treated grafts were measured in rabbits on a normal diet, and these levels were further increased with $1 \%$ cholesterol feeding (Fig. 4). Although monocyte binding to AS ODN-treated grafts was also higher than that to either ungrafted venous or arterial endothelium, this effect was significantly attenuated compared to control grafts in both normal and high-cholesterol states. Ex vivo inhibition of NOS activity with L-NAME increased monocyte binding to AS ODN-treated grafts, suggesting that the increased NOgenerating activity in these conduits contributed to their reduced affinity for inflammatory cells.

Increased VCAM-1 expression has been correlated with monocyte adhesion during atherogenesis (22), and therefore we examined this marker of vascular cell activation in our ODN-transfected grafts. VCAM-1 expression as detected by immunohistochemical analysis was reduced in grafts transfected with AS ODN directed against PCNA and cdc2 kinase. Untreated and control ODN-treated grafts demonstrated an upregulation of VCAM-1 on endothelial surfaces both at 2 and 4 wk after surgery, whereas AS ODN-treated grafts that remained free of significant neointimal hyperplasia maintained low or undetectable levels of VCAM-1 (Fig. 5). The endothelial cells of AS ODN transfected grafts, however, did retain the usual capacity for VCAM-1 upregulation, as demonstrated by their response to lipopolysaccharide.

\section{Discussion}

We have previously demonstrated that AS ODN blockade of vascular cell cycle progression renders vein grafts resistant to accelerated atherogenesis. Endothelial dysfunction correlates closely with the development of human and experimental atherosclerosis in native arteries as well as vein grafts $(4,12,13$, 23-29). In this study, we documented functional, molecular, and biochemical changes in the endothelium of untreated and control ODN-treated grafts 2-6 wk after surgery, even in the absence of high cholesterol or atherosclerosis. We postulate that these changes, including increased VCAM-1 expression and monocyte binding, result from the activation of vascular cells, and that they reflect the grafts' state of increased susceptibility to accelerated atherosclerosis when exposed to hypercholesterolemia compared to either ungrafted jugular vein or native carotid artery. Furthermore, these abnormalities may parallel changes in human vein grafts, which are known to develop a similar predisposition to accelerated atherosclerotic disease. The results of this study suggest that AS ODN blockade of cell cycle progression leads to biological and biochemical stabilization of the vessel wall and endothelium (even without 
exposure to atherogenic conditions), and that this stabilization contributes to the grafts' ability to resist disease. We further hypothesize that this stabilization results from an altered pattern of vascular cell activation.

Our data suggest a reduction in ecNOS activity in both untreated and control ODN-treated grafts that, consistent with previous reports, correlated with impaired vascular reactivity. This impairment may also result from disruptions in intracellular signal pathways, since, as has been previously shown (30), control grafts were able to respond to calcium ionophore activation of ecNOS, but lost almost all ability to relax in response to acetylcholine. Davies et al. have shown that these changes in endothelial function are not a permanent response of the venous endothelium to grafting, but can be reversed by reimplantation of grafts into the venous circulation (31). In this study we found that by inhibiting vascular cell cycle progression via an ex vivo gene therapy approach, these changes in ecNOS activity and vascular reactivity could be largely attenuated.

An elevated level of oxygen radical generation (believed to be an important factor in vessel wall oxidative state and atherogenesis), was found in control vein grafts both in normal and in cholesterol-fed rabbits, and these increases were blunted by AS ODN transfection. NO is believed to reduce superoxide levels both by direct interaction with oxygen radicals and by inhibition of superoxide anion generating enzymes (32-34). Since pharmacologic inhibition of NOS activity in AS ODNtreated grafts resulted in increased superoxide generation, we interpret these results to suggest that at least part of the protection of the genetically treated grafts from superoxide radicals may be related to their enhanced ecNOS activity.

One marker of vascular cell activation that may play a direct role in macrophage invasion and atherogenesis is upregulated expression of VCAM-1, a phenomenon also known to be influenced by increased vessel wall oxidative state (35). Whereas VCAM-1 upregulation is only seen in the leading edge of regenerating endothelium during neointima formation after carotid balloon injury (8), we observed persistently high VCAM-1 expression in untreated or control ODN-treated vein grafts (in which physical endothelial disruption is minimal, and reendothelialization is completed within 1-2 wk) at least 4 wk after grafting, even in the absence of a high-cholesterol diet. AS ODN-transfected grafts, however, exhibited minimal levels of VCAM-1. These grafts were able to respond to ex vivo LPS stimulation with VCAM-1 upregulation, indicating that our treatment did not directly alter these vessels' usual capacity to express VCAM-1. NO donors inhibit the stimulated endothelial upregulation of VCAM-1 in vitro $(36,37)$, and the increased ecNOS activity demonstrated in AS ODN-treated vein grafts may play a role in the lower levels of VCAM-1 expression seen in these vessels after grafting.

AS ODN-treated grafts also displayed a lower adhesiveness for monocytes, and, as has been shown in normal rabbit aorta (19), the blockade of NOS with L-NAME in these grafts resulted in increased monocyte binding. Restoration of vascular NO activity in AS ODN-treated grafts may inhibit monocyte-endothelial interaction by abrogating oxidant-responsive transcriptional pathways that regulate the expression of endothelial adhesion molecules and chemokines (36-38).

We hypothesize that interruption of cell cycle progression may have important consequences for the phenotype of endothelial and/or vascular smooth muscle cells, and that this phenomenon provides the mechanism for our observed preserva- tion of endothelial function. One possibility is that blockade of PCNA and cdc2 kinase expression stabilizes normal endothelial cell phenotype and function. However, we and others have observed patchy endothelial denudation immediately after grafting (39), and the regenrated endothelium therefore includes cells free from PCNA and cdc2 kinase blockade. In addition to the direct effect of AS ODN transfecion on the remaining majority of the endothelium, the preservation of endothelial function may therefore alternatively result from a modification of the paracrine influence of underlying SMC and neighboring endothelial cells. Cell cycle arrest of activated vascular SMC may result in a reduced expression of cytokines and other molecules that influence vessel wall biochemistry and the overlying endothelium. Since our method of transfection affects both endothelial cells and vascular SMC, we postulate that both processes may be important.

The data presented herein underscore the ability of acute interventions in gene expression to produce prolonged and diverse effects on the biology and pathophysiology of vascular tissue, and reflect the potential importance of such interventions in the treatment of vascular disease.

\section{Acknowledgments}

We thank M.A. Hing for assistance in manuscript preparation.

This research is supported by NIH grants HL-46631, HL-35252, HL-35610, HL-48638, HL-07708, HL-08779 and HL-08850, the American Heart Association Bugher Foundation Center for Molecular Biology in the Cardiovascular System, and the Fred and Edna Mandell Fund for Atherosclerosis Research. G.H. Gibbons is the recipient of a Robert Wood Johnson Foundation Minority Faculty Development Award. J.P. Cooke is the recipient of a Vascular Academic Award from the NHLBI, and an Established Investigator Award from the American Heart Association. V.J. Dzau is the recipient of a National Heart Lung and Blood Institute MERIT Award.

\section{References}

1. Campeau, L., M. Enjalbert, J. Lesperance, M.C. Bourassa, P. Kwiterowich, S. Wacholder, and A. Sniderman. 1984. The relation of risk factors to the development of atherosclerosis in saphenous vein bypass grafts and the progression of disease in the native circulation: A study 10 years after aortocoronary bypass surgery. N. Engl. J. Med. 311:1329-1334.

2. Brewster, D.C., A.J. LaSalle, J.G. Robinson, E.C. Strayhorn, and C.R. Darling. 1983. Factors affecting patency of femeropopliteal bypass grafts. Surg. Gynecol. \& Obstet. 157:437-442.

3. Mann, M.J., G.H. Gibbons, R.S. Kernoff, F.P. Diet, P. Tsao, J.P. Cooke, Y. Kaneda, and V. J. Dzau. 1995. Genetic engineering of vein grafts resistant to atherosclerosis. Proc. Natl. Acad. Sci. USA. 92:4502-4506.

4. Chester, A.H., G.S. O’Neil, S. Moncada, S. Tadjkarimi, and M.H. Yacoub. Low basal and stimulated release of nitric oxide in atherosclerotic epicardial coronary arteries. Lancet. 336:897-900.

5. Bossaller, C., G.B. Habib, H. Yamamoto, C. Williams, S. Wells, and P.D. Henry. 1987. Impaired muscarinic endothelium-dependent relaxation and cyclic guanosine 5 '-monophosphate formation in atherosclerotic human coronary artery and rabbit aorta. J. Clin. Invest. 79:170-174.

6. Verbeuren, T.J., F.H. Jordaens, L.L. Zonnekeyn, C.E. Van Hove, M.C. Coene, and A.G. Herman. 1986. Effect of hypercholesterolemia on vascular reactivity in the rabbit. Circ. Res. 58:552-564.

7. Ku, D.D., J.B. Caulfield, and J.K. Kirklin. 1991. Endothelium-dependent responses in long-term human coronary artery bypass grafts. Circulation. 83: 402-411.

8. Tanaka, H., G.K. Sukhova, S.J. Swanson, S.K. Clinton, P. Ganz, M.I. Cybulsky, and P. Libby. 1993. Sustained activation of vascular cells and leukocytes in the rabbit aorta after balloon injury. Circulation. 88:1788-1803.

9. Weidinger, F.F., J.M. McLenachan, M. Cybulsky, J.M. Gordon, H.A. Rennke, N.K. Hollenberg, P. Ganz, and J.P. Cooke. 1990. Persistent dysfunction of regenerated endothelium following balloon angioplasty of rabbit iliac artery. Circulation. 81:1667-1679.

10. Khan, B.V., S.S. Parthasarathy, R.W. Alexander, and R.M. Medford. 1995. Modified low-density lipoprotein and its constituents augment cytokine- 
activated vascular cell adhesion molecule-1 gene expression in human vascular endothelial cells. J. Clin. Invest. 95:1262-1270.

11. Loppnow, H., and P. Libby. 1990. Proliferating or interleukin 1-activated human vascular smooth muscle cells secrete copious interleukin 6. J. Clin. Invest. 85:731-738.

12. Galis, Z.S., M. Muszynski, G.K. Sukhova, E. Simon-Morrissey, E.N. Unemori, M.W. Lark, E. Amento, and P. Libby. 1994. Cytokine-stimulated human vascular smooth muscle cells synthesize a complement of enzymes required for extracellular matrix digestion. Circ. Res. 75:181-189.

13. Clinton, S.K., and P. Libby. 1992. Cytokines and growth factors in atherogenesis. Arch. Path. Lab. Med. 116:1292-1300.

14. Cooke, J.P., A.H. Singer, P. Tsao, P. Zera, R.A. Rowan, and M.E. Billingham. 1992. Antiatherogenic effects of L-arginine in the hypercholesterolemic rabbit. J. Clin. Invest. 90:1168-1172.

15. von der Leyen, H.E., G.H. Gibbons, R. Morishita, N.P. Lewis, L. Zhang, M. Nakajima, Y. Kaneda, J.P. Cooke, and V.J. Dzau. 1995. Gene therapy inhibiting neointimal vascular lesion: In vivo gene transfer of endothelialcell nitric oxide synthase gene. Proc. Natl. Acad. Sci. USA. 92:1137-1141.

16. Morishita, R., G.H. Gibbons, K.E. Ellison, M. Nakajima, L. Zhang, Y. Kaneda, T. Ogihara, and V.J. Dzau. 1993. Single intraluminal delivery of antisense cdc2 kinase and proliferating-cell nuclear antigen oligonucleotides results in chronic inhibition of neointimal hyperplasia. Proc. Natl. Acad. Sci. USA. 90: 8474-8478.

17. Zwolak, R.M., M.C. Adams, and A.W. Clowes. 1987. Kinetics of vein graft hyperplasia: association with tangential stress. J. Vasc. Surg. 5:126-136.

18. Cooke, J.P., A.H. Singer, P. Tsao, P. Zera, R.A. Rowan, and M.E. Billingham. 1992. Antiatherogenic effects of L-arginine in the hypercholesterolemic rabbit. J. Clin. Invest. 90:1168-1172.

19. Tsao, P.S., L.M. McEvoy, H. Drexler, E.C. Butcher, and J.P. Cooke. 1994. Enhanced endothelial adhesiveness in hypercholesterolemia is attenuated by L-arginine. Circulation. 89:2176-2182.

20. Klyachkin, M.L., M.G. Davies, E.Svendsen, J.H. Kim, M.F. Massey, L. Barber, R.L. McCann, and P.-O. Hagen. 1993. Hypercholesterolemia and experimental vein grafts: Acclerated development of intimal hyperplasia and an increase in abnormal vasomotor function. J. Surg. Res. 54:451-468.

21. Ohara, Y., T.E. Peterson, and D.G. Harrison. 1993. Hypercholesterolemia increases endothelial superoxide anion production. J. Clin. Invest. 91: 2546-2551.

22. Cybulsky, M.I., and M. A. Gimbrone, Jr. 1991. Endothelial expression of a mononuclear leukocyte adhesion molecule during atherogenesis. Science (Wash. DC). 251:788-791.

23. Berkenboom, G., P. Unger P, and J. Fontaine. 1989. Atherosclerosis and responses of human isolated coronary arteries to endothelium-dependent and -independent vasodilators. J. Cardiovasc. Pharmacol. 14:35-39.

24. Forstermann, U., A. Mugge, U. Alheid, A. Haverich, and J.C. Frolich. Selective attenuation of endothelium-mediated vasodilation in atherosclerotic human coronary arteries. Circ. Res. 62:185-190.

25. Jayakody, L., M. Senaratne, A. Thomson, and T. Kappagoda. 1987. Endothelium-dependent relaxation in experimental atherosclerosis in the rabbit. Circ. Res. 60:251-264.
26. Lüscher, T.F., D. Diederich, R. Stiebmann, K. Lehmann, P. Stultz, L. von Segesser, Z. Yang, M. Turina, E. Grädel, E. Weber, and F.R. Bühler. 1988 Difference between endothelium-dependent relaxation in arterial and in venous coronary bypass grafts. N. Engl. J. Med. 319:462-467.

27. Oneil, G.S., A.H. Chester, C.J. Schyns, S. Tadjkarimi, J.A.A. Borland, and M.H. Yacoub. 1994. Effect of surgical preparation and arterialization on vasomotion of human saphenous vein. J. Thorac. Cardiovasc. Surg. 107:699706.

28. Cross, K.S., M.G. Davies, M.N. El-Sanadiki, J.J. Murray, E.M. Mikat, and P.-O. Hagen. 1994. Long-term human vein graft contractility and morphology: a functional and histopathological study of retrieved coronary vein grafts. Br. J. Surg. 81:699-705.

29. Park, T.C., C.T. Harker, J.M. Edwards, G.L. Moneta, L.M. Taylor, and J.M. Porter. 1993. Human saphenous vein grafts explanted from the arterial circulation demonstrate altered smooth-muscle and endothelial responses. $J$. Vasc. Surg. 18:61-69.

30. Cross, K.S., M.N. El-Sanadiki, J.J. Murray, E.M. Mikat, R.L. McCann, and P.-O. Hagen. 1988. Functional abnormalities of experimental autologous vein graft neoendothelium. Ann. Surg. 208:631-638.

31. Davies, M.G., M.L. Klyachkin, H. Dalen, E. Svendsen, and P.-O. Hagen. 1993. Regression of intimal hyperplasia with restoration of endothelium-dependent relaxing factor-mediated relaxation in experimental vein grafts. Surgery (St. Louis). 114:258-271.

32. Hassoun, P.M., F.S. Yu, J.J. Zulueta, A.C. White, and J.J. Lanzillo. 1995. Effect of nitric oxide and cell redox status on the regulation of endothelial cell xanthine dehydrogenase. Am. J. Physiol. 268:809-817.

33. Munzel, T., H. Sayegh, B.A. Freeman, M.M. Tarpey, and D.G. Harrison. 1995. Evidence for enhanced vascular superoxide anion production in nitrate tolerance. A novel mechanism underlying tolerance and cross-tolerance. J. Clin. Invest. 95:187-194.

34. Niu, X.F., C.W. Smith, and P. Kubes. 1994. Intracellular oxidative stress induced by nitric oxide synthesis inhibition increases endothelial cell adhesion to neutrophils. Circ. Res. 74:1133-1140.

35. Marui, N., M.K. Offermann, R. Swerlick, C. Kunsch, C.A. Rosen, M. Ahmad, R.W. Alexander, and R.M. Medford. 1993. Vascular cell adhesion molecule-1 (VCAM-1) gene transcription and expression are regulated through an antioxidant-sensitive mechanism in human vascular endothelial cells. J. Clin. Invest. 92:1866-1874.

36. DeCaterina, R., P. Libby, H.-B. Peng, V.J. Thannickal, T.B. Rajavashisth, M.A. Gimbrone, Jr., W.S. Shin, and L.K. Liao. 1995. Nitric oxide decreases cytokine-induced endothelial activation. J. Clin. Invest. 96:60-68.

37. Tsao, P.S., R. Buitrago, J.R. Chan, and J.P. Cooke. 1996. Fluid flow inhibits endothelial adhesiveness: NO and transcriptional regulation of VCAM-1. Circulation. 94:1682-1689.

38. Zeiher, A.M., B. Fisslthaler, B. Schray-Utz, and R. Busse. 1995. Nitric oxide modulates the expression of monocyte chemoattractant protein 1 in cultured human endothelial cells. Circ. Res. 76:980-986.

39. Kohler, T.R., T.R. Kirkman, D. Gordon, and A.W. Clowes. 1990. Mechanism of long-term degeneration of arterialized vein grafts. Am. J. Surg. 160: 257-261. 